\title{
A qualitative and semiquantitative SEM study of the morphology of the biofilm on root surfaces of human teeth with endodontic-periodontal lesions
}

\author{
DARIAN RUSU ${ }^{1 *}$, STEFAN-IOAN STRATUL ${ }^{1}$, HORIA CALNICEANU ${ }^{1}$, MARIUS BOARIU ${ }^{2}$, \\ ALEXANDRU OGODESCU ${ }^{3}$, STEFAN MILICESCU $^{4 *}$, ANDREEA DIDILESCU $^{5}$, ALEXANDRA ROMAN $^{6}$, \\ PETRA SURLIN $^{7}$, COSMIN LOCOVEI $^{8}$, MONICA CHIPERI $^{9}$, SORINA SOLOMON $^{10^{*}}$ and LUMINITA NICA ${ }^{2}$ \\ Departments of ${ }^{1}$ Periodontology, ${ }^{2}$ Endodontics and ${ }^{3}$ Pedodontics, 'Victor Babes' University of Medicine and Pharmacy, \\ 300041 Timisoara; Departments of ${ }^{4}$ Prosthodontics and ${ }^{5}$ Embryology, 'Carol Davila' University of Medicine and Pharmacy, \\ 020021 Bucharest; ${ }^{6}$ Department of Periodontology, 'Iuliu Hatieganu' University of Medicine and Pharmacy, \\ 400000 Cluj-Napoca; ${ }^{7}$ Department of Periodontology, University of Craiova, 200349 Craiova; ${ }^{8}$ Department of Materials \\ and Manufacturing Engineering, Politehnica University of Timisoara, Timisoara 300006, Romania; \\ ${ }^{9}$ Private Practice, D-80539 Munich, Germany; ${ }^{10}$ Department of Periodontology, \\ 'Grigore T. Popa University of Medicine and Pharmacy, 700020 Iasi, Romania
}

Received July 17, 2020; Accepted August 17, 2020

DOI: $10.3892 /$ etm.2020.9331

\begin{abstract}
Over the last decades, scanning electron microscopy (SEM) proved to be invaluable for ultrastructural investigation, allowing imaging of the overall appearance and/or specific features of oral biofilms, e.g., microbial colonies and individual cells, glycocalyx, the presence of inorganic products. The aim of this study was the observation and evaluation of the morphology of the biofilm of endodontic-periodontal lesions (EPL) with a modified protocol involving a simplified histologic sample preparation and a low-vacuum SEM examination method. Twenty-one teeth with endodontic-periodontal involvement, extracted for periodontal reasons, were carefully washed with saline, underwent fixation in modified Karnovsky solution and were dehydrated in alcohol series. Samples were examined under low-vacuum SEM. Radicular surfaces were evaluated qualitatively and semiquantitatively for several characteristics, including the presence of bacterial types, the biofilm morphology and the content of root resorptions. Radicular surfaces were divided in four conventional zones Surfaces were evaluated for several characteristics: Presence of bacterial types, biofilm morphology, presence of root resorptions.
\end{abstract}

Correspondence to: Dr Marius Boariu, Department of Endodontics, 'Victor Babes' University of Medicine and Pharmacy, 9 Bulevardul Revolutiei din 1989, 300041 Timisoara, Romania

E-mail: boarium@yahoo.com

*Contributed equally

Key words: endodontic-periodontal lesions, biofilm, low-vacuum SEM, periopathogens, ultrastructure
High-quality images, relevant for endodontic-periodontal biofilms were collected. Continuous, established biofilm was found on all examined surfaces, its detection varying from $19 \%$ of the samples on the wall of cemental cone to $52.3 \%$ on the radicular surface of the periodontal pocket. Observed microorganisms included cocci, rods an filaments. Spirils and motile bacteria were only accidentally found. SEM investigation of surfaces involved in EPL revealed less surfaces covered by mature biofilm (in only $28.5 \%$ of the samples in the 'transition zone'), especially rods and filaments associated with cemental resorptions and calculus. Biofilm elements were better represented in periodontal pockets than in other zones of EPL (detected in up to $81 \%$ of the samples). A strong correlation between mature biofilm and the presence of cocci appears on all investigated zones $(\mathrm{P}<0.01)$. Microbiota appeared to be morphologically similar in apical and periodontal areas, especially in old EPL.

\section{Introduction}

Bacterial biofilm infections often involve aggregates of bacteria heterogeneously distributed throughout a tissue or on a surface (such as implanted medical devices). Identification of a biofilm infection requires direct visualization via microscopy, followed by characterization of the microbial community by culturing or sequencing-based approaches (1).

During recent years, extensive research has led to a better understanding of the etiology, pathogenesis and pattern of progression of periodontal diseases. Scanning electron microscopy (SEM) has contributed to this improvement, mainly with respect to histology of periodontal tissues, the description of the morphology and distribution of bacteria on the exposed root surface, analysis of the host-parasite interactions on the gingival pocket wall, and morphological evaluation of root 
treatment (2). Recently, it was suggested using SEM photographs that the cemento-enamel junction could act as a 'trap' to biofilm and calculus (3). Important progress has been made concerning the description of the endodontic biofilm associated with apical lesions (4-6). It was demonstrated that bacteria can live in biofilms and maintain endodontic infections within periapical lesions $(4,7)$.

SEM is an excellent, highly descriptive observation method for any type of biofilm. Structure of bacterial biofilms may be investigated using several variants of SEM (8). Low-vacuum SEM (so-called 'Wet-SEM') has been used in studies that evaluated the results of Nd:YAG laser irradiation used to remove the biofilm from periodontally-involved roots. The laser irradiation at 70-100 mJ, 20 pps for 2 sec caused surface cratering, areas of porosity, pitting, fissures, and lava-like structures, that were observed under Wet-SEM (9). Low vacuum SEM micrographs were used to observe the changes in the bacterial plasma-membrane of drug-resistant $S$. aureus and $P$. Aeruginosa bacterial cells treated with Macropin, a new antimicrobial (10).

The formation of biofilms in different environments, including clinical situations, has been studied intensively using a great variety of microscopic techniques. SEM is a precious tool for ultrastructural investigation of the general aspect of the biofilm and its characteristics: Bacterial species, individual bacterial cells, the glycocalyx and the presence of inorganic biofilm components. There are various descriptions of SEM use in biofilm assessment on implants, prosthetic devices, catheter, teeth or other solid structures in order to establish the role of biofilms in the persistence of infections (11-14). The conventional SEM technique needs a complicated procedure: Sample fixation in glutaraldehyde and/or in osmium tetroxide, followed by dehydration and coverage ('sputtering') of the biofilm with conductive metallic material (Gold, Palladium) or Carbon. The low-vacuum SEM observation method differs from traditional preparation protocols for SEM examination; the method is simple, quick and offers sample protection.

Endodontic infection may lead to bone resorption, development of periapical lesion and also extraradicular biofilm infection, as reported in two studies on teeth with therapy-resistant lesions $(4,7)$ and on teeth with pulp necrosis and chronic periapical lesions $(15,16)$. The endo-periodontal biofilm, situated on radicular areas of confluence between the endodontic and periodontal pathology, raises a special interest for researchers interested in SEM observation, due to its development on rough mineralized surfaces, subject to extension of plaque both from the root canal and from the periodontal pocket.

Although the distribution and morphology of the apical and radicular infections in periodontal pockets are well studied, there is no data until now in the literature regarding the morphology and the composition of the biofilm of combined endodontic-periodontal lesions (EPL).

The aim of this study was assessment of the biofilm on root surfaces of teeth with EPL with a modified protocol, using a simplified histological method to prepare specimens examined under low-vacuum SEM.

\section{Patients and methods}

Using aseptic surgical techniques and sterile instruments, 25 teeth with EPL diagnosed clinically and radiographically and with indication of extraction were extracted under local anesthesia in the Department of Periodontology of the 'Victor Babes' University of Medicine and Pharmacy of Timisoara, Romania. An informed consent was obtained from all patients and the study was approved by the Research Ethics Committee of the 'Victor Babes' University of Medicine and Pharmacy (ethics approval no. 12b/2009). In addition to severe EPL, the teeth had either deep circular periodontal defects (pocket depth over $7 \mathrm{~mm}$ ) with increased mobility, or advanced furcation involvement, or extensive carious destruction. All teeth were asymptomatic and had no fistula. For each tooth, the following data were recorded: The type of EPL (according to the Simon, Glick and Frank classification, 1971, based on the case history), the position of the periodontal pocket, the presence/absence of vitality, the existence of a root canal filling, the pocket depth, the clinical attachment level, the gingival recession, the plaque index PII (17), the bleeding on probing BOP, the furcation involvement (18), and the mobility (on the Miller scale). The clinical parameters were used for statistical correlations (data published elsewhere). These findings are included in Tables I and SI.

After extraction, the samples were carefully and gently rinsed with sterile saline solution, in order to avoid the disruption of the biofilm and to remove any biological material that could possibly come in contact with the root during the extraction (e.g., blood). The samples were prepared according to the protocol described by Noiri and Ebisu (5), modified for examination in low-vacuum SEM. For all further manipulation of the samples, delicate pliers were used only on the coronal third of the roots, in order not to disrupt the biofilm. The samples were introduced in vials for fixation in modified Karnovsky solution (glutaraldehyde $2.5 \%$, paraformaldehyde $4 \%$, sodium cacodylate $0.1 \mathrm{M}$ at $\mathrm{pH} 7.2-7.4$ ); the transportation of the vials to the laboratory took utmost care to prevent as much as possible the samples to touch the walls of the vials. In the Department of Histology of the 'Victor Babes' University of Medicine and Pharmacy of Timisoara, the samples were dehydrated in series of ethanol (70, 95 and 100\%), changed every 15 min. Because the prolonged immersion in $100 \%$ ethanol could irreversibly modify the aspect of the biofilm through extreme dehydration, only 3 samples at a time were dehydrated and then immediately examined under low-vacuum SEM in the laboratory of the Department of Mechanics and Material Resistance of the Politehnica University of Timisoara using the SEM Inspect $S$ (FEI), under pressures of 80-250 $\mathrm{Pa}$ and acceleration voltage of $15 \mathrm{kV}$. For samples with higher conductivity, the pressure used was $80 \mathrm{~Pa}$, while for those with lower conductivity the pressure used was $150 \mathrm{~Pa}$, as the conductivity is known to increase with the density of the examined biologic material.

Before SEM examination, all samples underwent a preliminary examination under a light microscope. Using sterile instruments, the samples were fixed in a special device with clamps, first in a vertical position to examine the apical part. After the examination of the apical part, each sample was inclined and then fixed horizontally for examination of the root surface corresponding to the periodontal pocket. The primary examination was performed under magnification x 50-x80, in order to localize the apical foramen or to select the main apical foramen in case there was more than one. The magnifications $\mathrm{x} 200$, x500 and x800 were used for the examination of the external radicular surface, for the areas of cemental and 
Table I. Identification and clinical characteristics of the teeth included in the study.

\begin{tabular}{|c|c|c|c|c|c|c|c|c|c|c|c|c|}
\hline Sample & Tooth & EPL type & $\begin{array}{l}\text { Site (perio } \\
\text { pocket) } \\
\text { position }\end{array}$ & Vitality & Endo tx. & PD & CAL & Rec. & PII & BOP & $\begin{array}{c}\text { Furcation } \\
\text { involvement }\end{array}$ & Mobility \\
\hline EP1 & 1.1. & EI-PII & $\mathrm{M}, \mathrm{V}$ & $\mathrm{N}$ & Y & 8 & 14 & 6 & 3 & $5 / 6$ & - & II/III \\
\hline EP2 & 1.1. & PI-EII & $\mathrm{D}$ & $\mathrm{N}$ & $\mathrm{N}$ & 10 & 12 & 2 & 2 & $4 / 6$ & - & II \\
\hline EP3 & 2.1. & PI-EII & M, D & $\mathrm{N}$ & $\mathrm{N}$ & 9 & 11 & 2 & 3 & $6 / 6$ & - & II/III \\
\hline EP4 & 1.8. & PI-EII & $\mathrm{V}, \mathrm{D}$ & $\mathrm{Y}$ & $\mathrm{N}$ & 8 & 8 & 0 & 2 & $6 / 6$ & 1 & - \\
\hline EP5 & 1.2. & EI-PII & $\mathrm{D}$ & $\mathrm{N}$ & $\mathrm{N}$ & 12 & 13 & 1 & 3 & $3 / 6$ & - & II \\
\hline EP6 & 4.6. (M) & EI-PII & $\mathrm{M}, \mathrm{V}, \mathrm{L}$ & $\mathrm{N}$ & $\mathrm{N}$ & 13 & 14 & 1 & 2 & $4 / 6$ & 3 & I/II \\
\hline EP7 & 4.1. & PI-EII & Circ. & $\mathrm{Y}$ & $\mathrm{N}$ & 7 & 14 & 7 & 2 & $6 / 6$ & - & III \\
\hline EP8 & 1.6. & EI-PII & M & $\mathrm{N}$ & $\mathrm{N}$ & 10 & 12 & 2 & 3 & $6 / 6$ & 2 & II/III \\
\hline EP9 & 2.5 & PI-EII & Circ. & $\mathrm{N}$ & $\mathrm{Y}$ & 12 & 12 & 0 & 2 & $4 / 6$ & - & - \\
\hline EP10 & 4.6. (D) & PI-EII & $\mathrm{D}, \mathrm{V}, \mathrm{L}$ & $\mathrm{Y}(1 / 2)$ & $\mathrm{N}$ & 14 & 16 & 2 & 1 & $3 / 6$ & 3 & I \\
\hline EP11 & 3.7. (M) & EI-PII & $\mathrm{M}, \mathrm{V}$ & $\mathrm{N}$ & $\mathrm{Y}$ & 12 & 13 & 1 & 1 & $2 / 6$ & 1 & I \\
\hline EP12 & 4.5. & PI-EII & $\mathrm{D}$ & $\mathrm{N}$ & $\mathrm{Y}$ & 6 & 8 & 2 & 1 & $3 / 6$ & - & I/II \\
\hline EP13 & 1.7. & PI-EII & Circ. & $\mathrm{Y}$ & $\mathrm{N}$ & 15 & 15 & 0 & 2 & $4 / 6$ & - & - \\
\hline EP14 & 1.7. & PI-EII & M & $\mathrm{N}$ & $\mathrm{Y}$ & 7 & 11 & 4 & 1 & $2 / 6$ & - & I/II \\
\hline EP15 & 1.7. & PI-EII & $\mathrm{M}, \mathrm{D}$ & $\mathrm{Y}$ & $\mathrm{N}$ & 14 & 15 & 1 & 2 & $5 / 6$ & 2 & II \\
\hline EP16 & 4.5. & PI-EII & Circ. & $\mathrm{N}$ & $\mathrm{Y}$ & 13 & 15 & 2 & 3 & $6 / 6$ & - & III \\
\hline EP17 & 3.8. & EI-PII & M & $\mathrm{N}$ & $\mathrm{N}$ & 12 & 13 & 1 & 2 & $3 / 6$ & 2 & I/II \\
\hline EP18 & 4.8. & PI-EII & M & $\mathrm{Y}$ & $\mathrm{N}$ & 10 & 14 & 4 & 2 & $3 / 6$ & 1 & II \\
\hline EP19 & 3.7. (M) & EI-PII & M & $\mathrm{N}$ & $\mathrm{N}$ & 11 & 11 & 0 & 2 & $3 / 6$ & 3 & $\mathrm{I} / \mathrm{II}$ \\
\hline EP20 & 1.4. & PI-EII & Circ. & $\mathrm{N}$ & $\mathrm{N}$ & 10 & 13 & 3 & 3 & $5 / 6$ & - & II/III \\
\hline EP21 & 3.1 . & PI-EII & Circ. & $\mathrm{N}$ & $\mathrm{N}$ & 12 & 14 & 2 & 3 & $4 / 6$ & - & II/III \\
\hline EP22 & 3.5 & EI-PII & Circ. & $\mathrm{N}$ & $\mathrm{Y}$ & 15 & 15 & 0 & 2 & $6 / 6$ & - & III \\
\hline EP23 & 4.3. & PI-EII & Circ. & $\mathrm{N}$ & $\mathrm{Y}$ & 14 & 14 & 0 & 3 & $5 / 6$ & - & III \\
\hline EP24 & 3.7. & PI-EII & $\mathrm{D}, \mathrm{M}$ & $\mathrm{N}$ & $\mathrm{N}$ & 11 & 14 & 4 & 3 & $4 / 6$ & 2 & III \\
\hline EP25 & 4.5 . & PI-EII & Circ. & $\mathrm{N}$ & Y & 11 & 12 & 1 & 2 & $3 / 6$ & - & II \\
\hline
\end{tabular}

PI-EII, Primary perio with secondary endo involvement ELP; EI-PII, Primary endo with secondary perio involvement ELP; Circ., Circular defect (crater); PD, Pocket Depth; CAL, Clinical Attachment Level; Rec., Recession; BOP, Bleeding on Probing, number of bleeding sites out of 6 probed sites; PI, Plaque Index of the tooth (measured on the available tooth surface).

dentinal resorptions, and for the detection of the presence of the bacterial film. Finally, the magnifications x1,000-x20,000 were used for the detection and characterization of the morphology of the microorganisms. The bacteria included in the biofilm, as well as the solitary microorganisms on the hard surfaces were morphologically categorized in cocci, rods, motile (spirochete, spyrils) and filaments. Through graphic delimitation of specific areas of pictures and using the Print screen function, the objects of interest were identified. The chronological list of these areas under increasing magnification was saved on a single Word document and registered under the tag of each sample, to make sure the identification of each object of interest can be re-traced at any time later.

For the SEM topographical examination of the biofilm, target zones on the apical surface of each sample were defined as follows: The internal wall of the cemental cone (its biofilm mostly seen as an extension of the root canal infection, sometimes in the presence of root canal filling materials); the near-foraminal (peri-foraminal, juxta-foraminal) zone (present in any typical chronic apical infection); the 'transition' zone between the near-foraminal and the periodontal pocket zone (of great interest in the hypothesis that it harbors biofilm with mixed morphology: Endodontic and periodontal); the periodontal pocket zone (harboring typical periodontal biofilm).

The 'transition' zone was considered to be limited apically by the marks of the former apical lesion (cemental resorptive lacunae for the cases of EPL with primary endodontic onset and for the very rare cases of simultaneous EPL) and coronally by the apical limit of the calculus deposits typical for periodontal pockets. For EPL with primary periodontal onset and no marks of resorbtion available, the 'transition zone' was considered to begin at $2 \mathrm{~mm}$ coronally to the crest of the cemental cone.

As the understanding of the radicular biofilm morphology needs a preliminary 'inspection' phase, a collection of characteristic SEM images was created, in order to provide typical visually recognizable elements for further reading of the images of the samples. Figs. 1-19 represent a selection of the most relevant images for the present study, included in the collection.

On all 5 zones, the following elements were qualitatively evaluated: The established biofilm, the glycocalyx matrix, the 


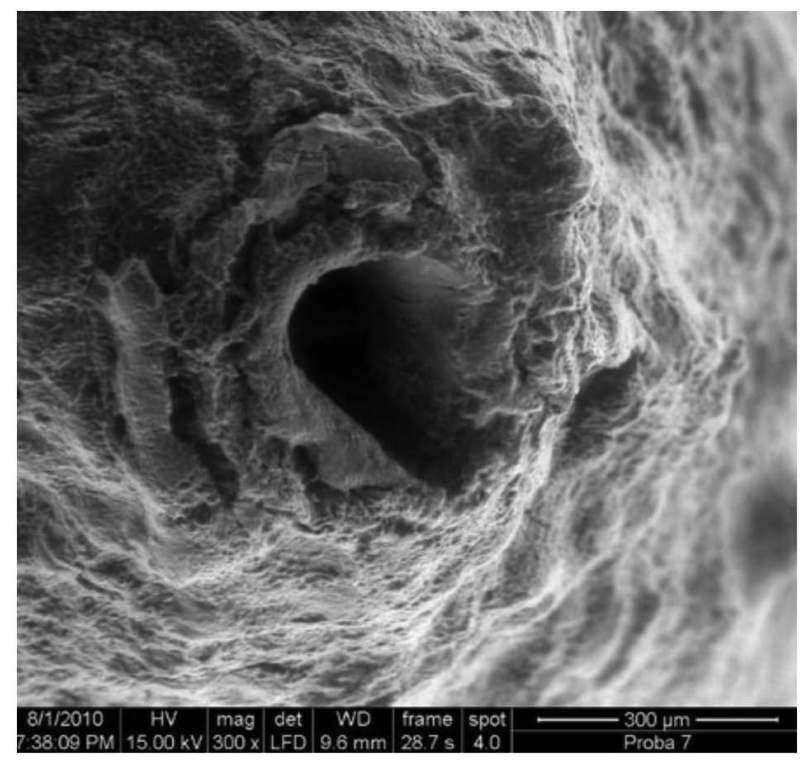

Figure 1. Internal wall of the cemental cone, x300.

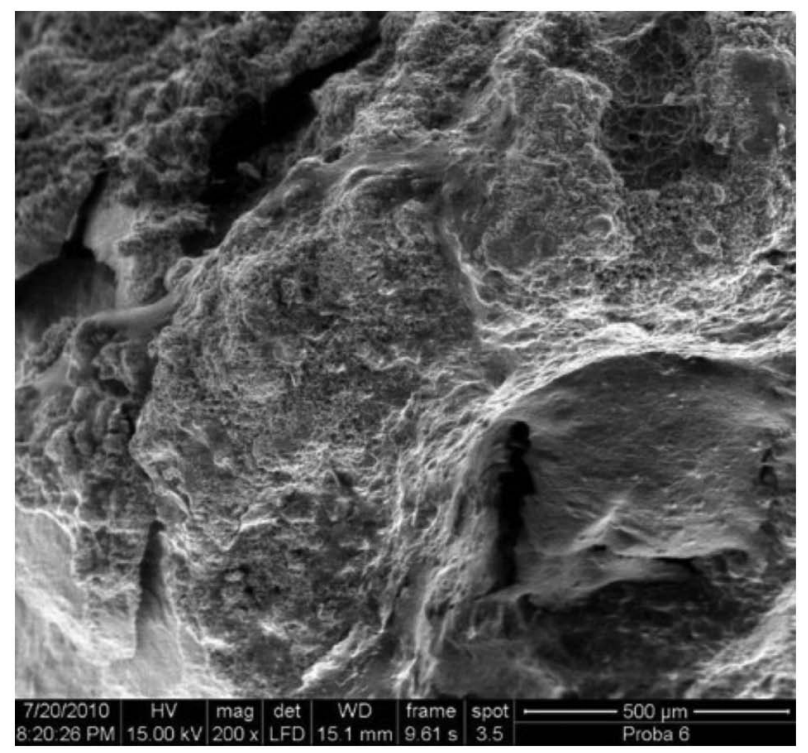

Figure 2. Near-foraminal zone, x200.

presence of isolated microorganisms, the relative presence of microbial morphologies - cocci, rods, filamentous forms, motile forms (spirochetes, spirilli), areas of nude cementum, lacunae of cemental resorption, the presence of calculus, the presence of unstructured (amorphous) material (debris), the presence of the root canal material (in cases with endodontic treatment), the presence of red blood cells as result of the extraction procedures (as they can mask the biofilm). The presence of these elements varied, depending on the zone. Specific elements noted in the near-foraminal zone were the periodontal ligament fibres, in various degrees of decomposition, depending on the vicinity with the EPL. In the near-foraminal zone, the transition zone and the periodontal pocket zone, the biofilm was sometimes found populating the interior of the cemental lacuna.

The SEM images were independently evaluated by one researcher (SS). Some of the above-mentioned elements were

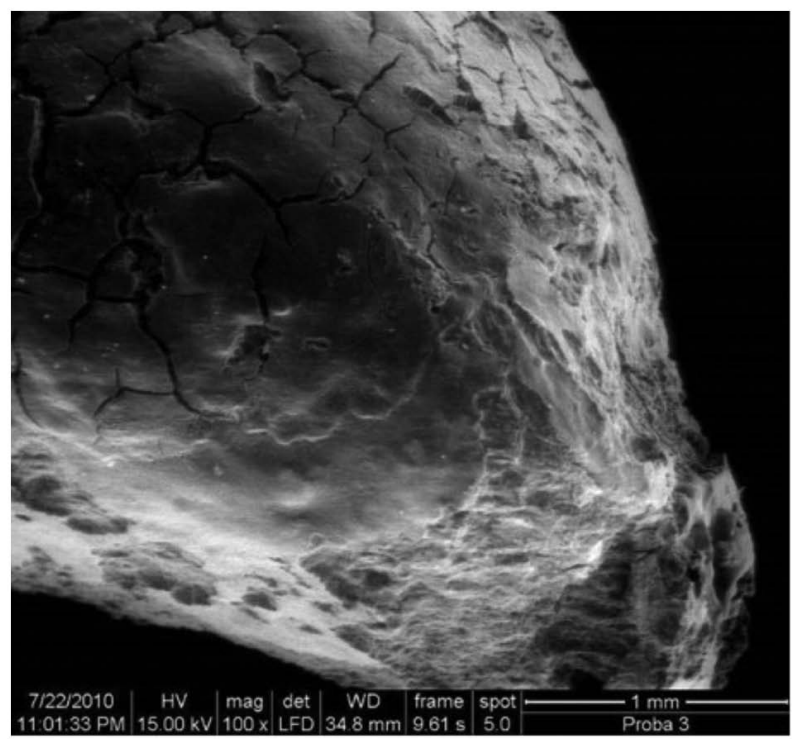

Figure 3. The 'transition' zone, limited apically by large strands of cemental resorbtions (underneath the former primary endodontic lesion) and coronally by a large calculus area inside the former periodontal pocket, $\mathrm{x} 100$.

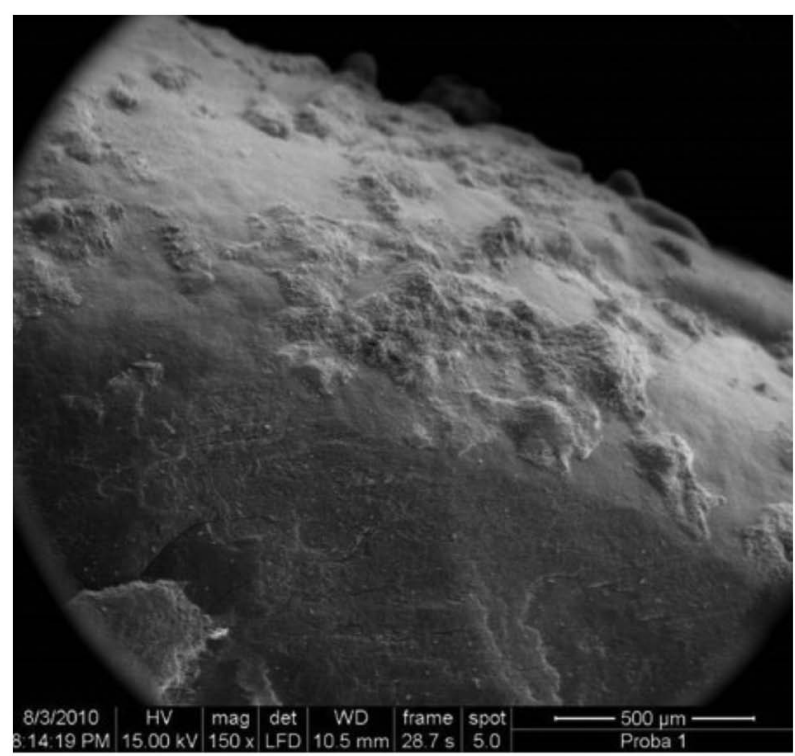

Figure 4. The radicular surface inside the periodontal pocket. Note the typical calculus covered with biofilm, x150.

defined semiquantitatively, as well. Depending on their quantity on the studied SEM images, the data were recorded by the examiner to the following categories: (score 0), absence; + (score 1), + 'low quantity'; ++ (score 2), 'significant quantity'; +++ (score 3), 'abundant'. The scores were used to establish statistical correlations.

The resorbtions (cemental lacunae) were separately analyzed, as they are considered zones of special agglomeration of the biofilm, by offering a particular shelter to the microorganisms. The analyzed alements in the resorbtion areas were: The character of the resorbtions (isolated, multiple, generalized); their near-foraminal presence (as indicating an old apical lesion), the SEM appearance of the lacunar relief (apparently shallow, apparently deep), 


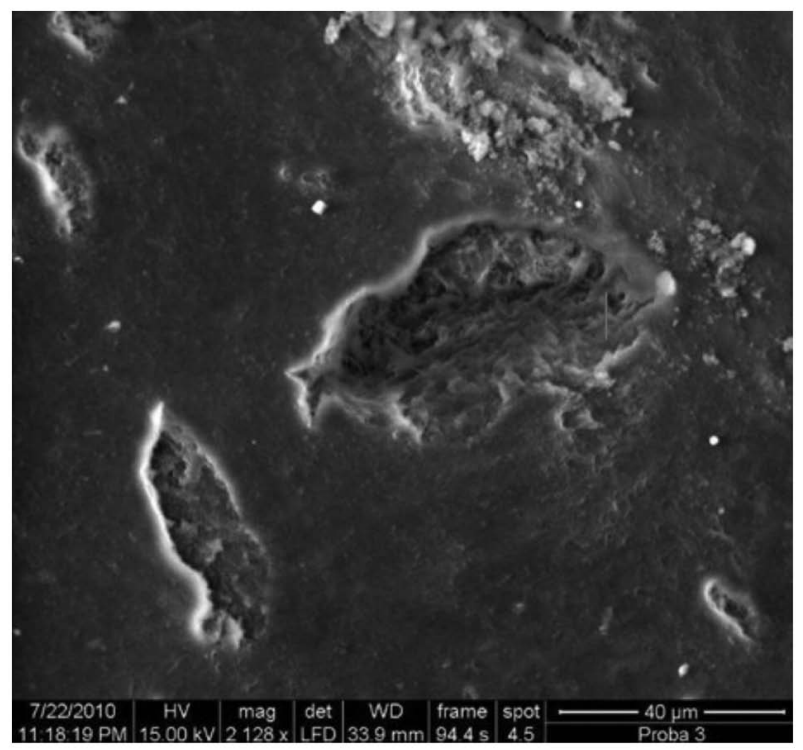

Figure 5. Isolated cemental lacunae on the root surface in the former periodontal pocket, $\mathrm{x} 2,120$.

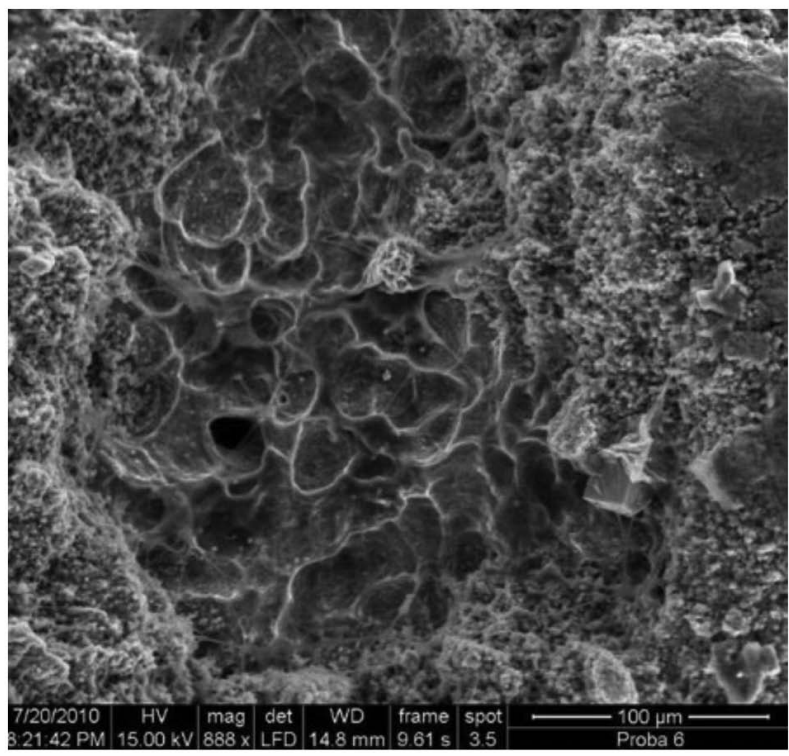

Figure 6. Multilocular cemental resorbtion (lacuna) surrounded by abundant biofilm. Filaments of glycocalyx can be noted across the lacuna, x890.

the presence of the established biofilm, the predominant morphology of the bacteria (cocci, rods, filaments, motile species), the presence of isolated bacteria. These values were qualitatively and quantitatively evaluated, as well, as described before.

Statistical analysis. The qualitative data for biofilm characteristics on all EPL zones was summarized by computing rates of prevalence. The relations between the biofilm characteristics assessed semiquantitatively were investigated using non-parametric correlational analysis (Spearman rho correlation coefficients and corresponding significance tests performed using significance level $\alpha=0.05$ ). The data were analysed using the software $\mathrm{R}$ version 4.0.0.

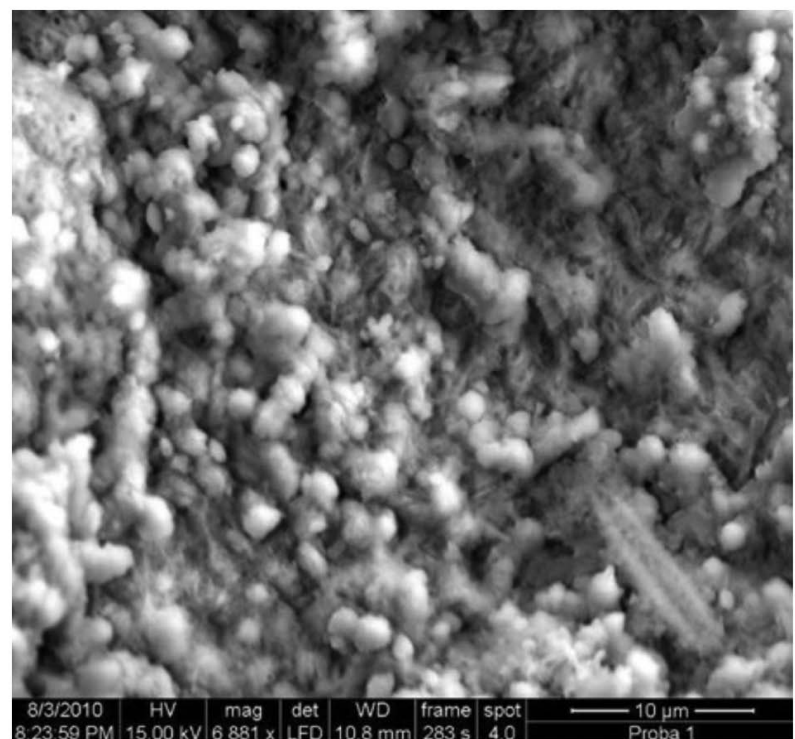

Figure 7. Detail of established biofilm, including glycocalyx, coccoid microorganisms and a large rod-like bacterium, x6,900.

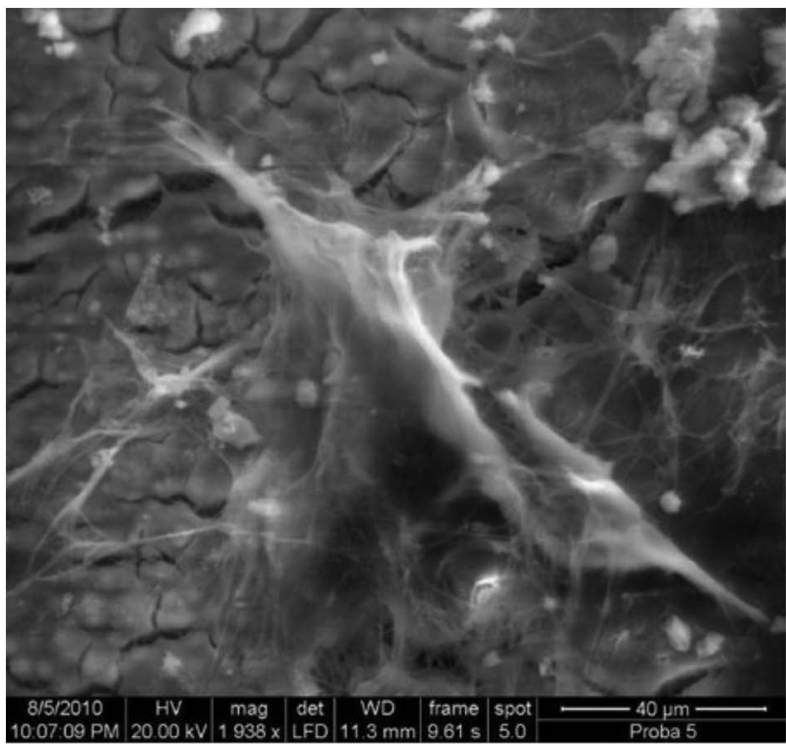

Figure 8. Isolated fragment of glycocalyx on the cemental surface, poor of bacteria, a probable result of early colonizers, x1,900.

\section{Results}

Four out of 25 samples were eliminated during the primary microscopic examination due to following reasons: Apex fully covered with calculus and no detectable apex, the complete absence of the biofilm and microorganisms (due possibly to incorrect manipulation of the sample), the abundant presence of residual periodontal fibres that prevented the determination of the target zones on the root surface. Thus, 21 teeth entered the examination. A total number of 44 images were selected for their quality and special relevance and were included in a separate collection (Figs. S1-S21). In all samples, the cementum presented near the apical foramen apparently shallow or deep areas of resorption of various shapes and dimensions, some including clusters of agglomerated, 


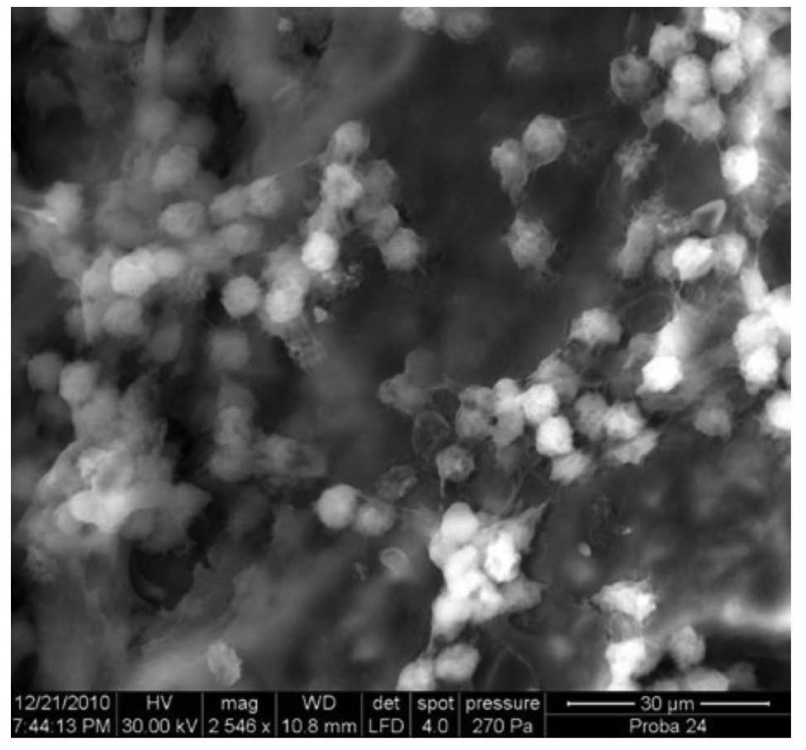

Figure 9. Low-density coccoid bacteria (early colonizers?), included in a minimal glycocalyx. Note the glycocalyx attachment strings to the cemental surface, $\mathrm{x} 2,500$.

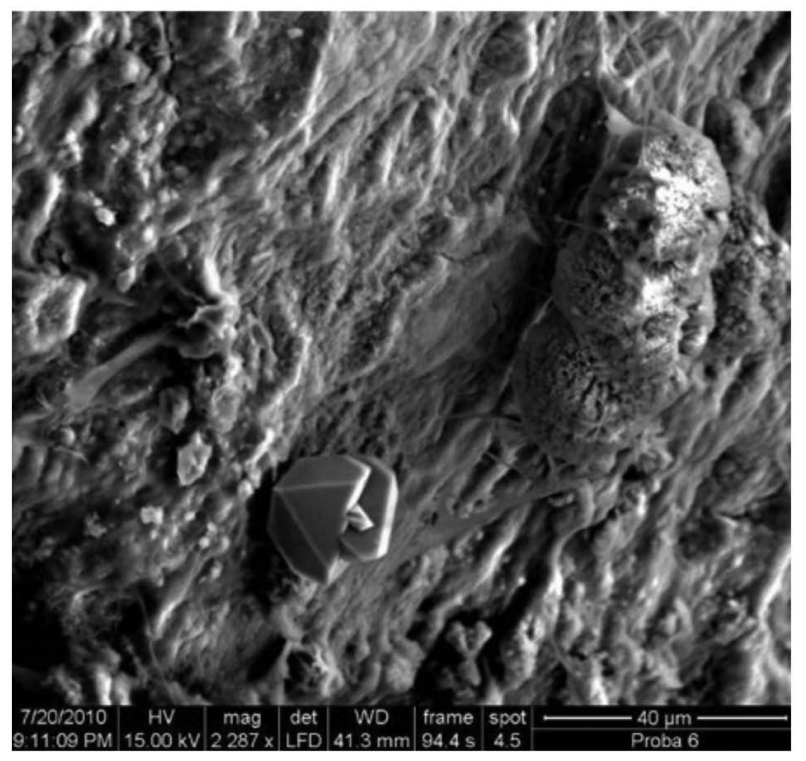

Figure 10. Torsade-shaped rod colony and a polyedric inorganic crystal on the root surface in the periodontal pocket, $\mathrm{x} 2,300$.

inserted residual collagen fibres. Within the biofilm in these cemental lacunae, microorganisms were present, either monomorphic (cocci, rods, filaments, motile forms), or in association. In some specimens, small resorbtion areas, containing biofilm, were noted on the intact cementum. Only $5(24 \%)$ teeth with EPL included in the study presented a mature biofilm on the inner surface of the cemental cone, and $2(9.5 \%)$ presented isolated microorganisms, 38\% cocci and $5 \%$ rods. In 3 samples (14\%), the matrix (glycocalyx) with few microorganisms was observed on the inner wall of the cemental cone.

On the near-foraminal zone, mature biofilm was found in 4 out of 21 samples (19\%) and isolated microorganisms only in 1 sample (4.7\%). The identified microorganisms were in $28.5 \%$

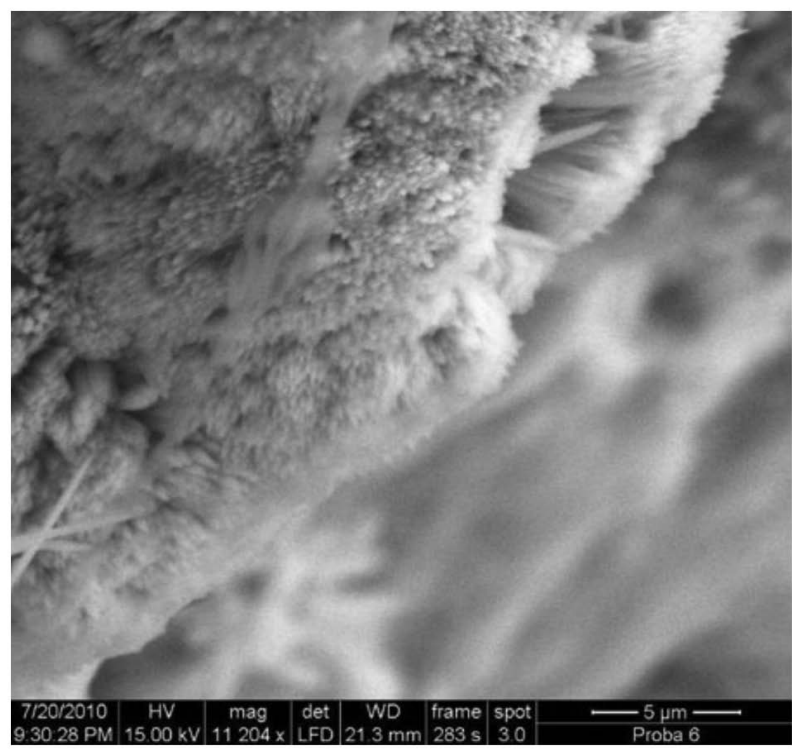

Figure 11. Detail of the torsade-shape colony, x11,200.

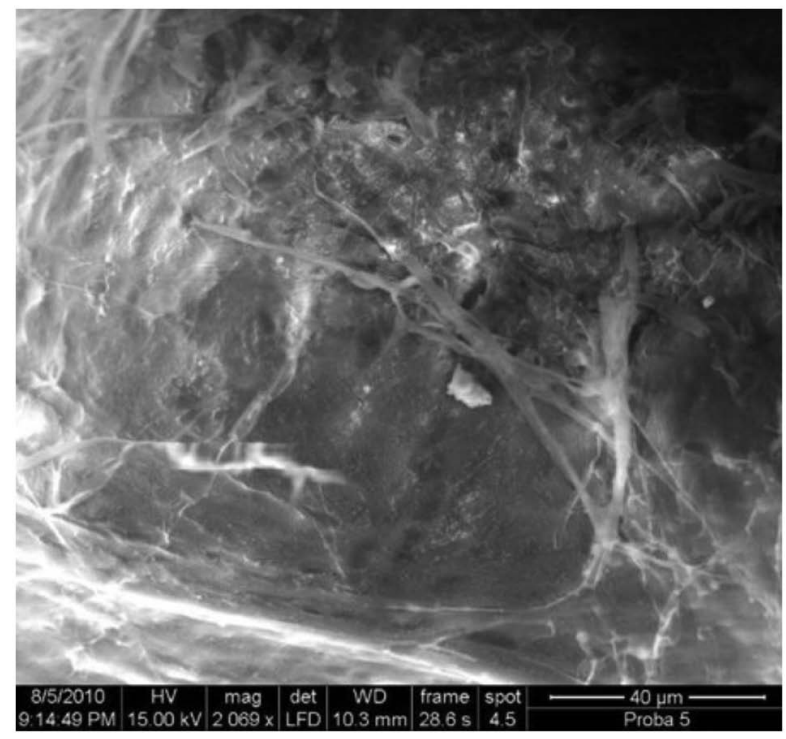

Figure 12. Isolated residual periodontral fibers near the apical foramen, $\mathrm{x} 2,100$.

of the samples cocci, in $9.5 \%$ of the samples rods, motile forms (spirilli) in only 1 sample (4.7\%). In 1 sample a matrix poor in microorganisms was found, and in another 1 sample isolated microorganisms.

In the 'transition' zone, mature biofilm was found in 8 out of 21 samples $(38 \%)$ and isolated microorganisms in 5 other samples $(24 \%)$. In $57 \%$ of the samples cocci were identified and in further $24 \%$ rods, filaments in $24 \%$ and no motile forms were found. In this zone 6 out of 21 samples $(28.5 \%)$ presented marked resorbtions; in 3 samples (14\%) the resorbtion lacunae were populated by biofilm. In $24 \%$ of the samples, the 'transition zone' presented residual periodontal fibers and $24 \%$ presented calculus.

In the periodontal pocket zone, especially on the calculus deposits, the biofilm percentage increased to $52.3 \%$ of the samples, $62 \%$ of these showed cocci, $38 \%$ rods, 


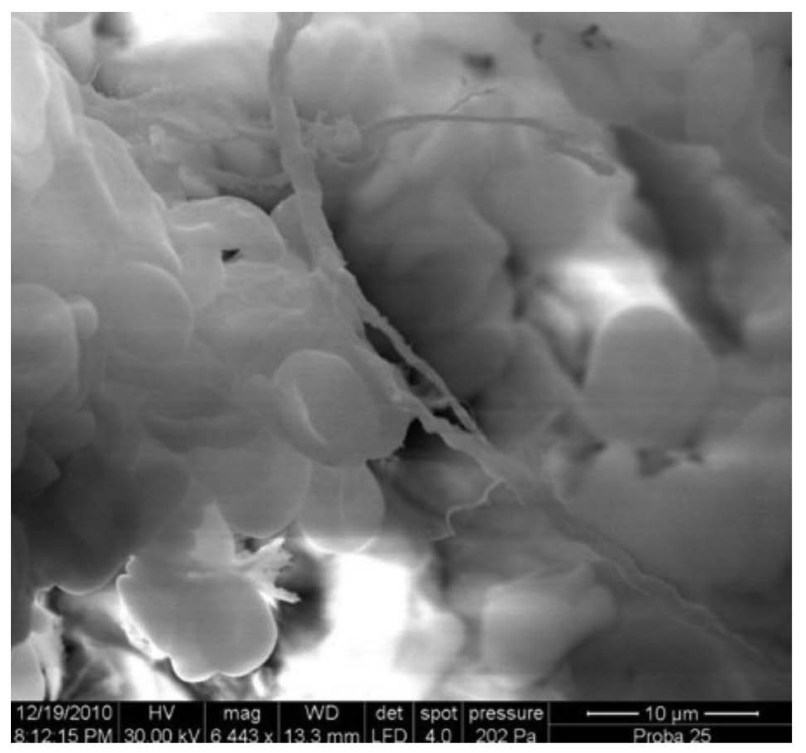

Figure 13. Isolated spyrils and red blood cells, x6,400.

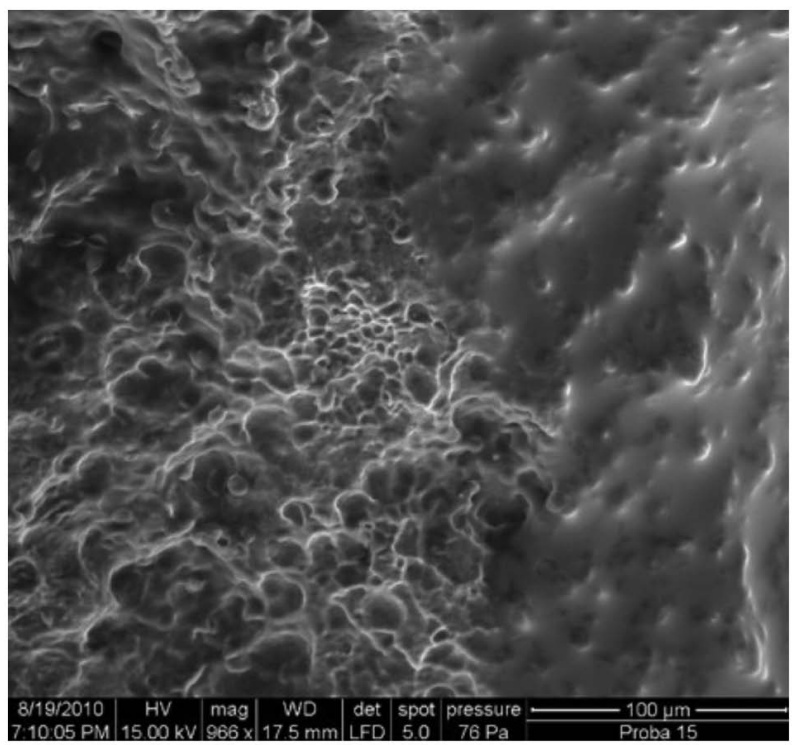

Figure 14. Normal cement adjacent to an area of resorbtion, x1,000.

$23.8 \%$ filaments but, surprisingly, no sample presented motile forms. Less resorbtions were found $(4.7 \%)$, residual periodontal fibers $(38 \%)$ and isolated bacteria (14.2\%).

The special separated analysis, of the biofilm in the cemental resorbtion lacunae, using the same criteria, revealed in $24 \%$ of the samples thick, mature biofilm (5 out of 24 samples), $52 \%$ presented cocci, $19 \%$ rods and no motile form or filament. Fig. 20 shows the frequency of the distributions of all investigated parameters, in all zones of interest.

The statistical analysis of the data revealed the presence of mature biofilm on the inner wall of the cemental cone in $24 \%$ of the samples; this drops to $19 \%$ in the near-foraminal zone and then increases to $38 \%$ in the 'transition zone' and to $52.3 \%$ in the periodontal pocket zone. Abundant quantity of biofilm was found only in the 'transition zone' $(9.5 \%)$ and in the periodontal pocket zone (19\%).

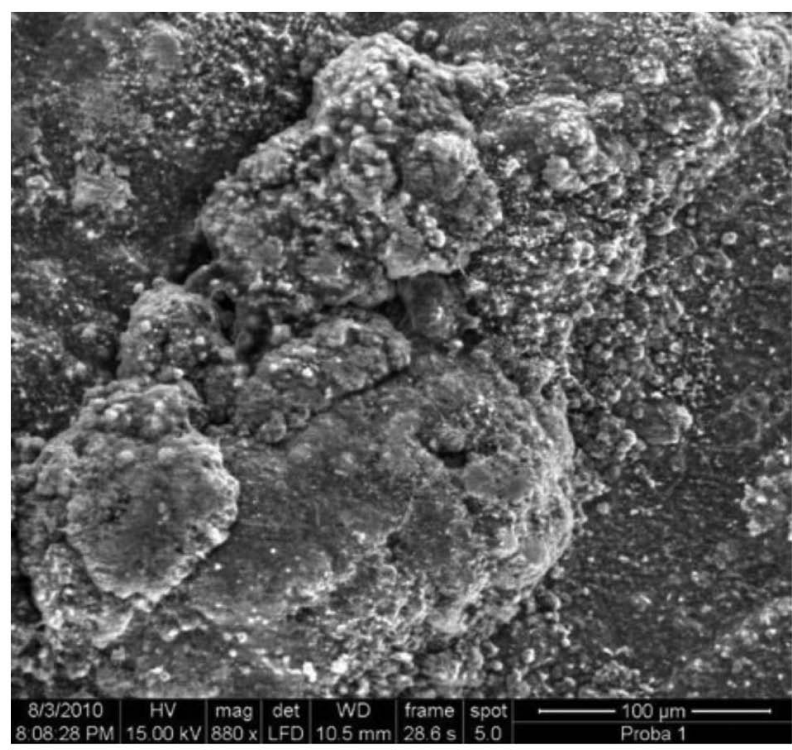

Figure 15. Massive thick calculus deposit in the periodontal pocket, $\mathrm{x} 900$

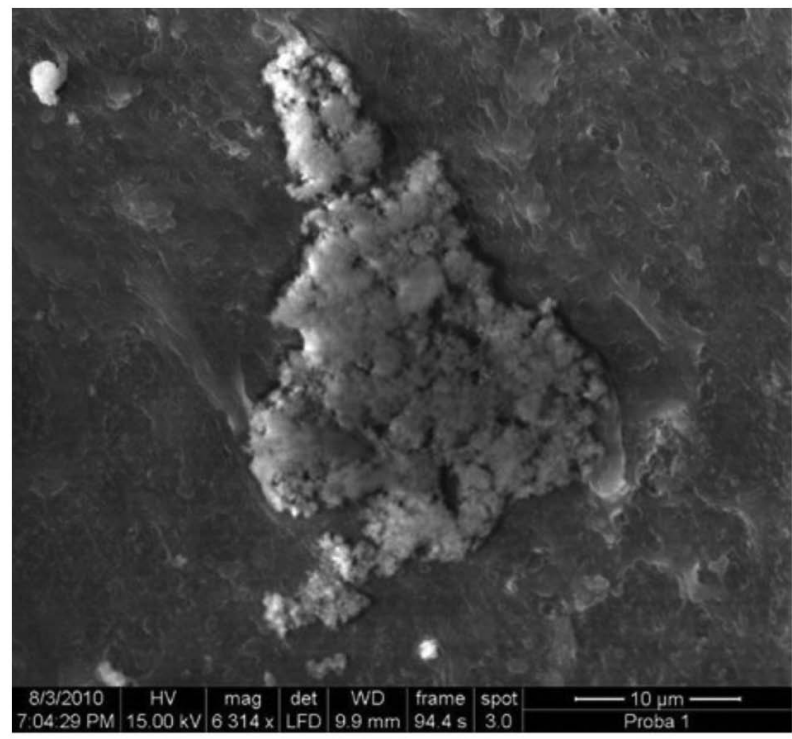

Figure 16. Unstructured amorphous debris on the nude cemental surface, $\mathrm{x} 6,300$.

The extracellular matrix (glycocalyx) poor in bacteria was found on the inner wall of the cemental cone in $14 \%$ of the samples, on the near-foraminal zone in $4.7 \%$ of the samples, in $9.5 \%$ in the 'transition zone' and more frequently in the periodontal pocket zone (14.2\%). An appreciable amount of extracellular matrix poor in microorganisms was found only in the 'transition zone' in $9.5 \%$ of the samples.

Isolated microorganisms were found in $9.5 \%$ of the samples on the inner wall of the cemental cone, $4.7 \%$ in the near-foraminal zone, in $24 \%$ of the samples in the 'transition zone' and in $14.2 \%$ of the samples in the periodontal pocket zone. In the 'transition zone', in $9.5 \%$ of the samples, the quantity of isolated microorganisms found was abundant.

The coccoid morphology was found in $38 \%$ of the samples on the inner wall of the cemental cone, in $28.5 \%$ in the juxtaforaminal zone, in $57 \%$ of the samples in the 'transition zone', 


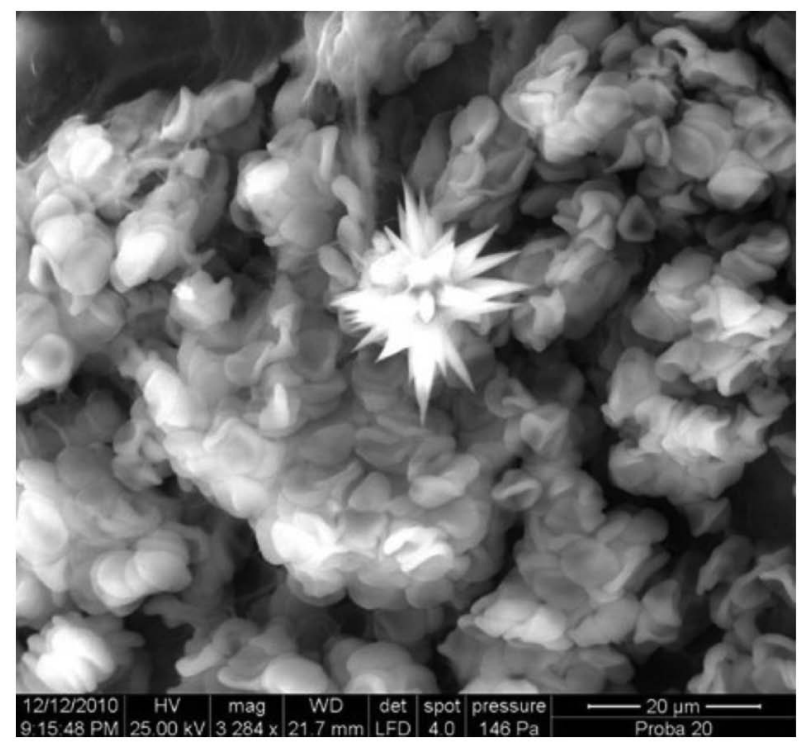

Figure 17. Star-like crystal (talcum crystal?) fixed over a dehydrated blood clot, $x 3,300$.

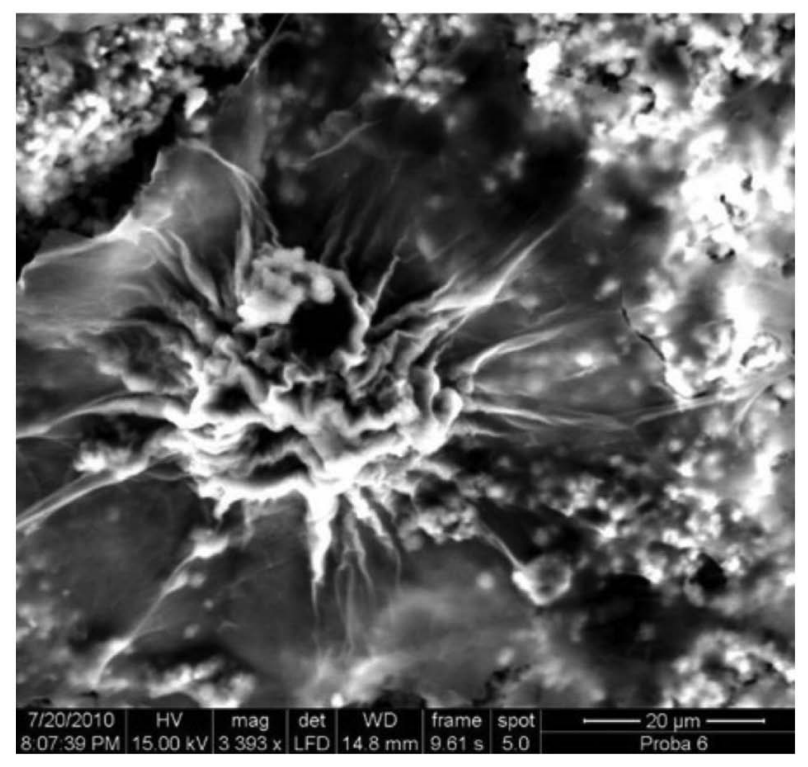

Figure 18. Efflorescent circular patch of glycocalyx, including later microcolonies, layered over previous abundant biofilm, x3,900.

and in $62 \%$ in the periodontal pocket samples. Abundant accumulations of cocci were found in the near-foraminal zone in $4.8 \%$ of the samples, in $19 \%$ of the samples in the 'transition zone' and in $14.3 \%$ of the samples in the periodontal pocket zone.

The proportion of the rods increased from $5 \%$ of the samples on the the inner wall of the cemental cone to $9.5 \%$ in the near-foraminal zone, $14 \%$ in the 'transition zone' and to $38 \%$ in the periodontal pocket zone. An abundant quantity was found only in the periodontal pocket zone, in $4.8 \%$ of the samples. Filamental morphology of the bacteria was found neither on the inner wall of the cemental cone zone, nor in the near-foraminal zone, but in $24 \%$ of the samples on the 'transition zone' (4.8\% in abundant quantity) and in $23.8 \%$ of the samples in the periodontal pocket zone.

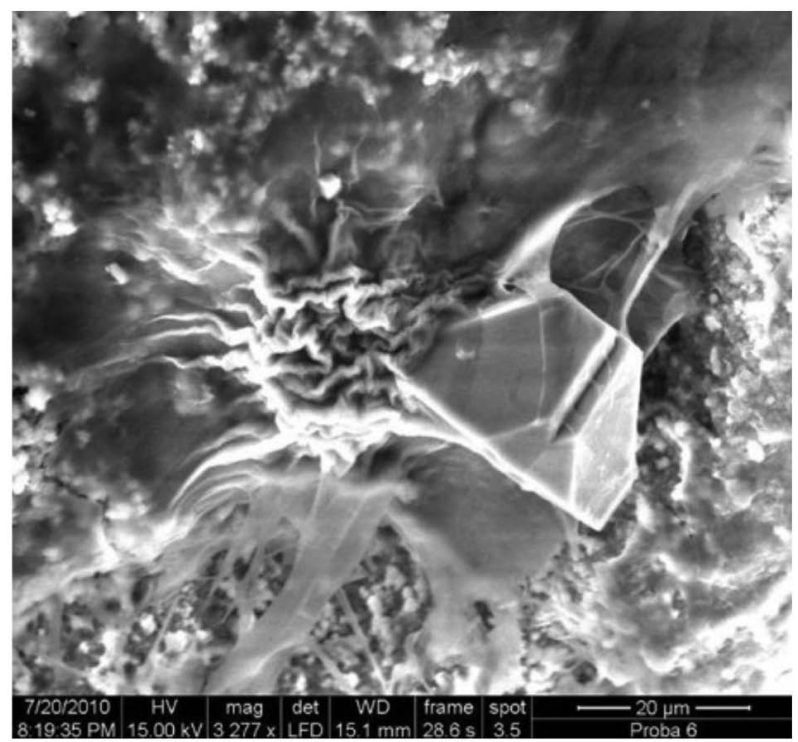

Figure 19. Recent efflorescent superficial microcolony, including a polyedric crystal, x3,300.

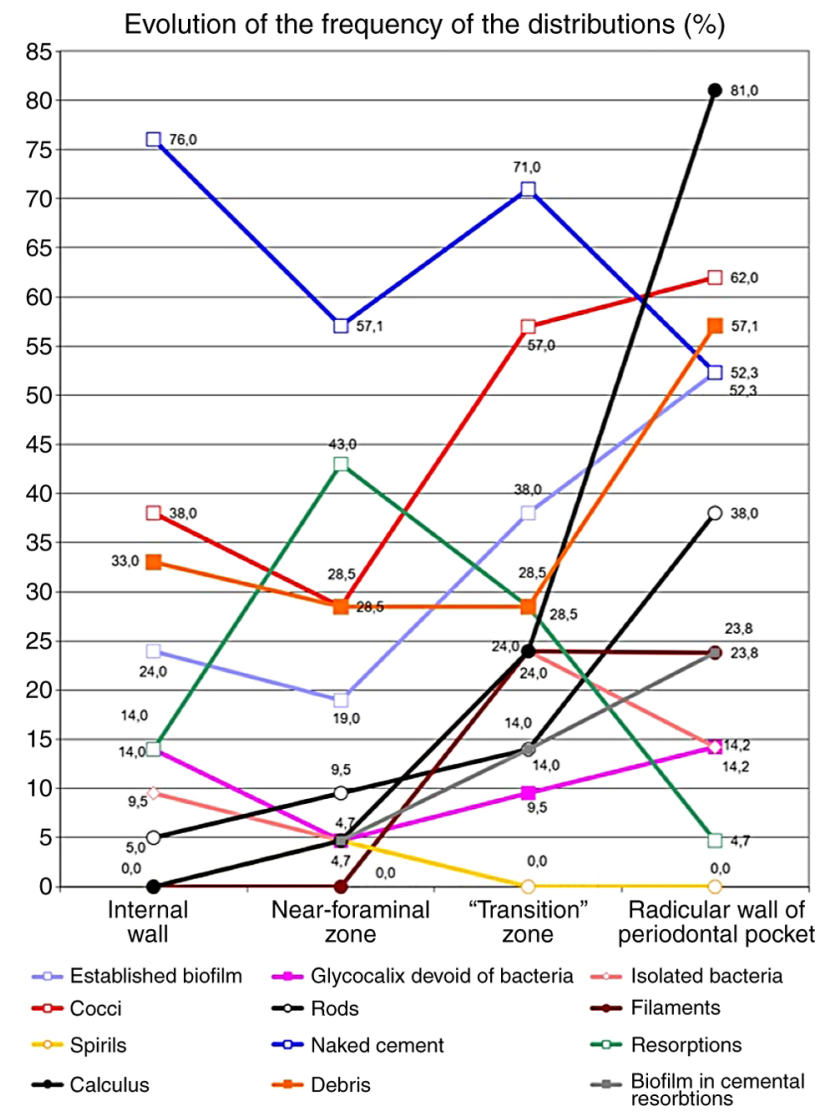

Figure 20. Synthetic graphic representation, with linear markers of the frequency of the distributions of all investigated parameters, in all zones of interest.

Under SEM observation, motile forms (spirils/spirochetes) were found only in the near-foraminal zone in $4.7 \%$ of the samples in reduced quantity (4.8\% of the samples). The cemental resorbtions were found in $14 \%$ of the samples on the inner wall of the cemental cone, in $43 \%$ of the samples in 
Table II. Significant correlations between the investigated parameters (Spearman's rho and corresponding P-values). ${ }^{\mathrm{a}}$

\begin{tabular}{|c|c|c|c|}
\hline Variable 1 & Variable 2 & Spearman's rho & P-value \\
\hline Established biofilm (1) & Cocci (1) & 0.79 & $<0.001$ \\
\hline Established biofilm (1) & Established biofilm (2) & 0.61 & 0.004 \\
\hline Established biofilm (1) & Established biofilm (3) & 0.47 & 0.033 \\
\hline Glycocalyx devoid of bacteria (1) & Glycocalyx devoid of bacteria (2) & 0.55 & 0.010 \\
\hline Glycocalyx devoid of bacteria (1) & Isolated bacteria (2) & 0.79 & $<0.001$ \\
\hline Isolated bacteria (1) & Isolated bacteria (2) & 0.79 & $<0.001$ \\
\hline Isolated bacteria (1) & Isolated bacteria (3) & 0.50 & 0.022 \\
\hline Cocci (1) & Established biofilm (2) & 0.66 & 0.001 \\
\hline Cocci (1) & Cocci (2) & 0.92 & $<0.001$ \\
\hline Rods (1) & Rods (2) & 0.69 & 0.001 \\
\hline Rods (1) & Rods (3) & 0.58 & 0.006 \\
\hline Resorptions (1) & Resorptions (2) & 0.62 & 0.003 \\
\hline Resorptions (1) & Resorptions (3) & 0.64 & 0.002 \\
\hline Established biofilm (2) & Cocci (2) & 0.72 & $<0.001$ \\
\hline Rods (2) & Calculus (2) & 0.69 & 0.001 \\
\hline Rods (2) & Rods (4) & 0.54 & 0.012 \\
\hline Calculus (2) & Biofilm in cemental resorptions (2) & 1.00 & $<0.001$ \\
\hline Established biofilm (3) & Cocci (3) & 0.84 & $<0.001$ \\
\hline Cocci (3) & Cocci (4) & 0.51 & 0.018 \\
\hline Calculus (3) & Rods (4) & 0.52 & 0.015 \\
\hline Calculus (3) & Calculus (4) & 0.47 & 0.033 \\
\hline Established biofilm (4) & Cocci (4) & 0.89 & $<0.001$ \\
\hline Established biofilm (4) & Filaments (4) & 0.75 & $<0.001$ \\
\hline Established biofilm (4) & Naked cementum (4) & -0.76 & $<0.001$ \\
\hline Glycocalyx devoid of bacteria (4) & Isolated bacteria (4) & 1.00 & $<0.001$ \\
\hline Rods (4) & Calculus (4) & 0.49 & 0.024 \\
\hline
\end{tabular}

${ }^{a}$ The numbers in parentheses denote zones where the parameters were evaluated: (1) Internal wall of the cemental cone, (2) juxta-foraminal zone, (3) transition zone, (4) periodontal pocket zone, (5) cemental lacunae.

the near-foraminal zone, in $28.5 \%$ in the 'transition zone' and $4.7 \%$ in the zone of the periodontal pocket. Biofilm was found inside the resorbtion lacunae in $4.7 \%$ of the samples in the near-foraminal zone, $14 \%$ in the 'transition zone' and $23.8 \%$ in the periodontal pocket zone.

Calculus was not found on the inner wall of the cemental cone, but it was found in $4.7 \%$ of the samples in the near-foraminal zone, in $24 \%$ of the samples in the 'transition zone', and in $81 \%$ of the periodontal pocket zone samples. In $9.5 \%$ of these samples, the quantity found was considered abundand. The correlational analysis for each parameter on all four investigated zones is represented in Table II.

\section{Discussion}

As far as the authors know, this is the first SEM study of the biofilm of EPL. This is also the first study describing a radicular 'transition' zone at the intersection of the endodontic and periodontal microbiota. It is also evident that, the older the lesion, the fewer the morphological differences in the biofilms of adjacent regions, which raises the question of common characteristics for endodontic and periodontal lesions.
The low-vacuum SEM examination of bacterial biofilm on root surfaces proved useful in the present study because the method allowed the preservation of samples and avoided high electrostatic loads during examination. The sample preparation method for low-vacuum SEM examination differs from the usual SEM preparation method for biologic samples, in which the dehydration of the samples is completed by using $\mathrm{CO}_{2}$ in drying devices at a critical point, followed by fixation of the samples with adhesive conductive silver on metallic support discs, and the sputtering of samples with 5-10 nm of pure gold to make them conductive. This protocol is described minutiously by Leonardo et al (19), indicating a thickness of $200 \mu \mathrm{m}$ of the gold sputtering coating. Another protocol completes the dehydration of the samples in a lyophilization device using t-butylic alcohol, and sputters the samples with osmium oxyde with a $5 \mathrm{~A}$ thick conductive layer obtained with a plasma-multicoater device (6). Both described methods are technique-sensitive and expensive.

In this study, the dehydratation procedere in increasing alcohol concentrations was completed with a light air-blow for a few seconds. The dehydratation was maximized by lowering the pressure inside the microscope vat up to $80-250 \mathrm{~Pa}$ 
(low-vacuum). This procedure extracts all alcoholic remnants from the samples, carefully and at slow pace. Despite the careful induction of the low-vacuum, several samples presented signs of biofilm disruption, bacterial body damage and root surface cracks, indicating further need for a better control of the experimental procedure.

The SEM observations focused on a root surface including the continuum root surface inside the periodontal pocket - a so-called 'transition zone' (between the apical part of the root surface inside the periodontal pocket and the former initial apical lesion, corresponding to the former confluence zone between them), the near-foraminal zone (the surface of the apex inside the former apical lesion), the inner wall of the cemental cone. Part of the continuum described above is the 'plaque-free-zone' (PFZ) described by Brady (20), a near-apical root zone situated in the periodontal pocket underneath the most apical extension of the calculus tartar, where bacteria organized as biofilm (plaque) tend to disappear, as a consequence of the permanent and sustained cell defence of the host near the epithelial junction. In our experiment, it was considered that the conventional zones delimitated as above are potentially containing biofilm with noteworthy individual characteristics.

The delimitation of the observation zones on the root surface was conventional and not without difficulties. The morphology serving to delimitation of both the inner wall of the cemental cone and the near-foraminal zone was relatively clear. The 'transition' zone was apically delimited by the typical landmark of the former apical lesion (cemental resorbtions with typical texture and clear limits in EPL with primary endodontic origin and in the rare case of combined simultaneous EPL) and coronally by the apical limit of calculus deposits existant in the periodontal pockets. In the case of primary periodontal EPL, the 'transition' zone was conventionally defined as starting at $2 \mathrm{~mm}$ distance from the periforaminal crest. In this study, the endo-periodontal microbial population organized as a biofilm, was studied in all 4 conventional zones described: The inner wall of the cemental cone, the near-foraminal zone, the 'transition' zone, the periodontal pocket zone. The observations followed the variations of distribution of characteristic morphological elements of the biofilm in a continuous mode, from the terminal zone of the root canal to the radicular wall of the periodontal pocket. A first conventional division of the peri-foraminal region of apices with pulpal infections and apical lesions of pulpal origin is known in the literature as 'extraradicular zone'. This described the apical external zone, outside the root canal $(4,7,19,21)$. A study from 2005 explains that the term 'extraradicular zone' is used clinically in contrast to the 'root canal', that defines anatomically the apical foramen (21). Although the 'extraradicular zone' is situated inside the chronic periapical lesion, it is considered distinct of the lesion. The lesion represents the volume of resorbed alveolar bone around the apex, which often contains granulation tissue. The approximately $2 \mathrm{~mm}$ area around the apical foramen (designated in our study as 'near-foraminal' or 'juxta-foraminal' zone) was separately investigated only in one study (15).

The morphology of the bacteria and biofilms on apices associated with refractory and chronic periapical periodontitis was thoroughly investigated in a classic study (6). Another
SEM study of the periodontal biofilm investigated seven perio-pathogenic bacteria in the biofilm of the "plaque-free zone' by scanning immunoelectron microscopic techniques, using both secondary and back-scattered imaging, with rabbit antibodies specific for each bacteria (5). Brady (20) described first the PFZ as an area on the root of extracted teeth, situated between the apical plaque limit and the epithelial attachment. The area raised interest for many researchers in the past (22-24). Brady observed that this zone displayed a surprisingly low number of bacteria, hence its name. Today, it is considered that the apical limit of this zone is not clearly delimited. The PFZ is situated adjacent to the epithelial attachment, and the bacteria found seem to resist the antimicrobial host response, whereas most of the microorganisms found at the apical limit of this region are destroyed (25). Starting from the concept of PFZ, in our study the limits of the 'transition' zone were defined between the bottom of the former periodontal pocket and the former apical lesion.

In our study, the frequency of detection of mature biofilm was found only in $24 \%$ of the samples on the inner wall of the cemental cone, in $19 \%$ of samples in the near-foraminal zone (zone corresponding to the former endodontic lesion), and is constantly increasing with distance to the apical foramen: $38 \%$ in the 'transition' zone and $52.3 \%$ in the periodontal pocket. In the literature, available data vary greatly. A study on 21 extracted teeth found apical biofilm and microorganisms in all investigated samples with pulpal necrosis and radiographically visible lesions (19). These results match the results of another study using an optical microscope, which detected the biofilm in 10 out of 16 extracted teeth with pulpal necrosis and periapical granuloma (26), but contradict the data described by later research, that found biofilm only on $3.7 \%$ of the teeth with apical necrosis and periapical lesions (27). More recently, mature extraradicular biofilm was found in 20 out of 27 patients with refractory apical periodontitis (21). Finally, established biofilm was found on 106 roots with apical periodontitis bacteria, with only one exception. The same study noted that the presence of biofilm in cysts, abscesses and granulomas was 95,83 and $69.5 \%$, respectively (28). A microbiological study reported the microbial colonization of the external apex surface of teeth with pulpal necrosis and apical periodontitis with cocci, rods, coccobacilli, filaments, spirochetes and the presence of biofilm in the apical $2 \mathrm{~mm}$, in the vicinity of the foramen, in $83.3 \%$ of the cases (15). The literature includes reports of biofilms with large masses of microorganisms on teeth with long-term endodontic lesions and periapical lesions, constituted from various morphotypes-cocci, bacilli and filaments (29). This demonstrates the heterogeneity of microbial colonization in long-term apical lesions, as shown by a series of studies $(4,16,30)$.

In addition to the data found in the current literature, (e.g., the frequency of presence of mature biofilm), our study recorded various other relevant data: The matrix poor in microorganisms, the presence of isolated microorganisms, semiquantitative data on the composition of the biofilm with respect to the microbial morphology (cocci, rods, filaments, motile forms), the presence of resorptions, of calculus, of periodontal residual fibers, of amorphous debris.

The comparative distribution of the matrix poor in microorganisms follows surprisingly the same pattern: $14 \%$ of samples 
on the inner wall of the cemental cone, decreases to $4.7 \%$ in the near-foraminal zone, increases to $9.5 \%$ in the 'transition' zone and to $14.2 \%$ in the periodontal pocket. The scientific interest for the study of the biofilm matrix poor in microorganisms and for isolated bacteria, is justified by a study on experimentally infected teeth in monkeys, that found no periapical bacterial colonies (31). The authors concluded that extraction or surgical procedures may lead to contamination of the periapical tissues and subsequently to possible false-positive findings in human samples. The presence of a matrix poor in microorganisms on the apical radicular surface can be explained, in our opinion, either by a primary colonization stage (implausible in EPL, because of their remote onset) or to local defense mechanisms against biofilm accumulation, possible characteristic for EPL. On the contrary, the total absence of matrix and biofilm (the so-called 'naked cementum') may be due to the destruction of biofilm during the histological sample preparation.

The existing literature does not present data regarding the presence of the different bacterial morphologies in the apical and periodontal biofilm. A classic study observed a morphological variety of cocci, rods and filaments, as well as associations between rods and filaments (19). These results matched the results of another study, that found bacteria, yeasts and biofilm in the vicinity of the foramen, in the areas of radicular resorption and on the external surface of human teeth apices with pulpal necrosis and chronic apical lesions (16). Some later studies identified the bacterial species in the biofilm with PCR immunohistochemical methods, insisting on the role of $P$. gingivalis in the primary extraradicular colonization (21). Our SEM study shows semiquantitative data on the relative proportion of the coccoid morphologies (cocci being considered primary colonizers) in the 4 experimental zones. Abundant accumulations of cocci were found in the near-foraminal zone in $4.8 \%$ of the samples, in $19 \%$ in the 'transition' zone and, in $14.3 \%$ of the samples in the periodontal pocket zone, and very little on the inner wall of the cemental cone.

Rods were found in our study in $5 \%$ of the samples on the inner wall of the cemental cone, $9.5 \%$ in the near-foraminal zone, $14 \%$ in the 'transition' zone and to $38 \%$ in the periodontal pocket zone. An abundance of rods was found only in the periodontal pocket zone in $4.8 \%$ of the samples in agreement with literature data (5). Coccoid microorganisms were observed in this study mostly on the biofilm surface (probably during release phases from clusters), and in monomorphic and mixed agglomerations. In an in vitro study on gutta-percha cones, it was found that cocci were localized in deeper biofilm layers, as they play an important role in the biofilm initiation (32).

In contradiction to the data from the literature, that found rods and filaments on the entire peri-foraminal and extraradicular area (a real 'eruption' of filaments) (5), in our study filaments were not found on the inner wall of the cemental cone zone, neither in the juxta-foraminal zone, but in $24 \%$ of the samples in the 'transition' zone (4.8\%, in abundance) and in $23.8 \%$ of the samples in the periodontal pocket zone. The rods and filaments populating the terminal root canal are described in the literature as in equal quantity with the cocci (4), situation which was not found in this study.

Finally, spirils/spirochetes were found only in the near-foraminal zone in $4.7 \%$ of the samples in low quantities. There is no explanation for their absence, except that they might be captured in the deeper biofilm layers, which prevented their visibility under SEM. Spirochetes associated with endodontic and periodontal infections were described in the 'plaque-free-zone' (20), their dimensions were measured as 140 microns long and 2 microns thick, longer and thicker as treponema (33). They were found in the $2 \mathrm{~mm}$ near the apex of teeth with pulpal necrosis and periapical lesions (15). Another study detected spirochetes longer than 20 microns (5). None of these studies detected motile forms in EPL, while the only spirilar form detected in our study was 25 microns long and 1.5 microns thick. The fact that motile bacteria and filaments were not observed in our study does not mean they do not exist in the biofilm of EPL, they could be hidden in deeper layers of the biofilm, inaccessible to free observation from above.

As a general observation, in our study we found a common variation of detection frequency of all investigated characteristics: A slight decrease or no change from the inner wall of the cemental cone to the near-foraminal zone, followed by a slight raise towards the transition zone, and a more pronounced increase towards the periodontal pocket zone.

Of special interest for our research was the distribution of cemental resorptions and their population with isolated and aggregated bacteria. This study includes observation of SEM characteristics of cemental resorptions in EPL, important for biofilm formation and persistence (e.g., frequency, relative depth, localization, fiber- and biofilm content). The incidence of radicular resorptions as potential sites for persistent biofilm on 39 apical thirds of extracted teeth was evaluated in a recent study (34). All samples presented irregular resorption areas with different depths, different configurations and extensions, especially localized around the apical foramen. It is already shown that cemental resorption of teeth with apical lesions were deep and included the whole peri-foraminal surface (19), whereas external resorptions were found only in few specimens (5). Our study found the highest frequency of cemental resorptions in the juxta-foraminal zone (43\% of the samples), zone that presented a high incidence ( $9.5 \%$ of the samples). This distribution is a logical consequence of the prolonged presence of the chronic apical lesion in the near-foraminal zone, which initiates and maintains the cementoclastic processes that lead to resorptions.

On the contrary, our study found biofilm in the cemental lacunae. There are data in the literature that show the retention and colonization of microorganisms in the cemental resorption sites $(4,16)$. In 1973, Brady (20) found a population of short and long bacilli, spirochetes and filaments in cemental resorptions in the 'plaque-free-zone'. All these data are connected by the concept of bacterial adhesion by Quirynen et al (35), in which the roughness of the surface and the free superficial energy of the solid substrate play an important role. On a rough surface, the bacteria are more protected against the detachment forces, so the change from reversible to irreversible attachment takes place easier and more often. This is illustrated in our study by the presence of biofilm in the cemental lacunae: In $4.7 \%$ of the samples in the near-foraminal zone, $14 \%$ in the transition zone and $23.8 \%$ in the periodontal pocket zone. The increased frequency of biofilm detection in the 'transition' zone (in $4.8 \%$ of samples considered even as abundant) is interesting, when compared with the near-foraminal zone, 
demonstrating the influence of the periodontal lesion on the apical microbiology. The findings in this study show a coexistence of resorption sites with abundant microorganisms and areas of naked radicular cement with absolutely no bacteria. The finding of a 'perfect hide-away' of cemental resorptions for the biofilm shows once again its resistance to therapeutic measures.

The images in this study show the existence and persistence of bacterial colonies organized as biofilm also in fissures of hard radicular surfaces, in cementum and calculus deposits. The decisive influence of the surface roughness and free superficial energy on the bacterial adhesion and biofilm formation is demonstrated in this study by the relation between the frequency of calculus distribution (in $4.7 \%$ of the samples in the juxta-foraminal zone, in $24 \%$ in the 'transition' zone samples, and in $81 \%$ of the periodontal pocket zone samples, as expected) and the presence of mature biofilm: The comparison of the graphics of the two distributions reveals the increase from the apical foramen to the periodontal pocket. Despite this, in our study we found areas covered by calculus but free of biofilm, even inside the periodontal pocket, demonstrating possible biofilm disruptions during the preparation of the samples.

The presence of residual periodontal ligament fibers and their relation with the biofilm microorganisms in the apical region was recently studied in a group of 18 teeth (36). In teeth with normal healthy pulp and with necrotic pulp but without radiographic visible apical lesions, the apical surfaces were covered with collagen fibers in the total absence of bacteria, whereas in necrotic teeth with radiographic visible lesions, the apices did not present collagen fibers, but areas of resorption with microorganisms were found in all samples. In contrast with these findings, the present study on EPL found residual periodontal ligament fibers in $14.2 \%$ of the samples in the juxta-foraminal zone, in $24 \%$ of the samples in the 'transition' zone and in $38 \%$ of the samples from the periodontal pocket zone. Moreover, periodontal fibers were found inside the cemental resorptions, with an abundant and various microbial content. These findings are in contradiction with the findings of Leonardo et al (19), but in accordance to the findings of the Nakano-Hasegawa et al (29), which found bacterial biofilm in all teeth with pulpal necrosis and periapical lesions, where the necrosis affected the periapical ligaments and the external surface of the apex $(19,29)$. In accordance with our findings, the latter study found a superior structure and organization of the biofilm, with a greater microbial mass of various morphotypes (cocci, rods, filaments) (29). This may prove, according to several researchers, the heterogeneity of microbial colonization in long-term lesions $(16,30)$. It can also be noted that the periodontal ligament destructions in EPL appears diminished and fragmented, when compared with circumscribed apical lesions.

While not specifically studying the bacterial coaggregation in biofilms (the recognition of genetically distinct cell types and their adhesion) (37), this study revealed a special morphologic coaggregation type in endo-periodontal biofilms. Apart from monomicrobial multiplication without detachment, coaggregation is one of the two mechanisms in biofilm formation. Special examples for biofilm inter-microbial coaggregation in the periodontal biofilm are the 'corncob' formation, in which streptococci adhere to filaments of Bacterionema matruchotii (38) or bacterial filaments on which Gram-negative rods adhere (39). The coaggregation type observed in our study has the aspect of a spheroid bacterial agglomeration covered with a glycoproteic matrix with circular extensions, situated over the mature biofilm, with a general aspect of 'wrinkled flower'.

Rods and filaments were correlated to the presence of rough calculus surfaces. Generally speaking, the strong correlation between mature biofilm and the presence of cocci appears in all investigated zones, while the presence of rods and filaments appeared to depend on the roughness of the surfaces (calculus and cemental resorptions). Data in our study indicate a strong correlation between the microbial flora of the three EPL zones, regardless of the organization form of the microflora (biofilms or isolated bacteria), provided rough surfaces due to calculus or resorptions are available.

The SEM investigation of the radicular surfaces involved in EPL in our study revealed less surfaces covered by biofilm than expected. There is no explanation for this observation, knowing also that the resistance to antimicrobial therapy of EPL is attributed to the persistence and inaccessibility of the biofilm.

Limitations of the present study include the conventional choice of the radicular zones and of the morphological characteristics of the biofilm. The interpretation of the results was done with caution, because of the age of the EPL, the frequency of acute episodes in apical lesions and periodontal pockets and the risk of biofilm destruction during sample preparation.

Several conclusions can be drawn from the present study. The SEM investigation of radicular surfaces involved in EPL revealed less surfaces covered by biofilm than expected. The microbial morphologies described by the present SEM investigation were mostly coccoid forms, seldom rods or filaments. Spirochetes were found only accidentally. These findings are contradictory to literature data.

Our data showed that the mature biofilm appears to be associated with the roughness of the support, due especially to the presence of cemental resorptions and calculus. Despite the communication between the periapical lesion and periodontal pocket, the biofilm elements seem to be better represented in the periodontal pocket than in other zones of the EPL.

The present study found relatively little correlative data. The strong correlation between the mature biofilm and the presence of cocci appears on all investigated zones, and the presence of rods and filaments appear to depend on the rugosity of the surfaces (calculus, cemental resorptions); the data indicate a strong correlation between the microbiota of the 3 zones in the EPL. On the contrary, the correlations found might confirm a similar organization of the apical and periodontal microbiota, especially in old EPL. Later on, the data of the present study should be completed with combined analyses SEM-TEM (for visualization of the horizontal distribution and composition of the biofilm); histobacteriological and immunobacteriological analysis for detection of microbiological species in correlation with clinical parameters of affected teeth (mobility, pocket depth and sensitivity to percussion); accurate analysis of the coaggregation and association in the biofilm; correlations between the biofilm presence and the success of therapeutic measures, because EPL tend to resist treatment. 


\section{Acknowledgements}

The authors would like to thank Eng. Dr Cosmin Locovei for his invaluable help in the SEM analysis and documentation, and Mr. Cristian Popescu and Mrs. Claudia Zaharia for their kind assistance with the statistical analysis of the data.

\section{Funding}

No funding was received.

\section{Availability of data and materials}

The datasets used/analyzed in this study are available from the corresponding author upon reasonable request.

\section{Authors' contributions}

SIS, DR, CL and LN participated in the sample collection and data acquisition. AR, PS, MC, AO and DR participated in the study design. SIS and LN drafted and critically revised the manuscript for important intellectual content. HC, MB and SM drafted and critically revised the manuscript for important intellectual content, and were also involved in the conception of the study. SS and AD performed the statistical analysis. All authors read and approved the final version of the manuscript.

\section{Ethics approval and consent to participate}

The study was approved by the Research Ethics Committee of the 'Victor Babes' University of Medicine and Pharmacy in Timisoara, Romania (ethics approval no. 12b/2009). All subjects were informed about the nature and the purpose of the study, and each subject signed an informed consent document giving permission for the dental procedures and sampling of biological material.

\section{Patient consent for publication}

Not applicable.

\section{Competing interests}

The authors declare that they have no competing interests.

\section{References}

1. Fritz B, Stavnsbjerg C, Markvart M, Damgaard PB, Nielsen SH, Bjørndal L, Qvortrup K and Bjarnsholt T: Shotgun sequencing of clinical biofilm following scanning electron microscopy identifies bacterial community composition. Pathog Dis 77: ftz013, 2019.

2. Carrassi A, Abati S and Santarelli G: The role of scanning electron microscopy in periodontal research. Scanning Microsc 2: $1123-1138,1988$

3. Satheesh K, MacNeill SR, Rapley JW and Cobb CM: The CEJ: A biofilm and calculus trap. Compend Contin Educ Dent 32: 30 , 32-37, quiz 38, 40, 2011

4. Tronstad L, Barnett F and Cervone F: Periapical bacterial plaque in teeth refractory to endodontic treatment. Endod Dent Traumatol 6: 73-77, 1990.

5. Noiri Y and Ebisu S: Identification of periodontal disease-associated bacteria in the 'plaque-free zone'. J Periodontol 71: 1319-1326, 2000.
6. Noiri Y, Ehara A, Kawahara T, Takemura N and Ebisu S: Participation of bacterial biofilms in refractory and chronic periapical periodontitis. J Endod 28: 679-683, 2002.

7. Tronstad L, Barnett F, Riso K and Slots J: Extraradicular endodontic infections. Endod Dent Traumatol 3: 86-90, 1987.

8. Karcz J, Bernas T, Nowak A, Talik E and Woznica A: Application of lyophilization to prepare the nitrifying bacterial biofilm for imaging with scanning electron microscopy. Scanning 34: 26-36, 2012.

9. Jeng JH,Chen KW, Lin CP, Chou HG and Lan WH: Ultrastructural changes of the tooth root surface by Nd:YAG laser irradiation followed by citric acid and tetracycline. J Formos Med Assoc 98: 242-247, 1999.

10. Ko SJ, Kim MK, Bang JK, Seo CH, Luchian T and Park Y: Macropis fulvipes venom component macropin exerts its antibacterial and anti-biofilm properties by damaging the plasma membranes of drug resistant bacteria. Sci Rep 7: 16580, 2017

11. Speer AG, Cotton PB, Rode J, Seddon AM, Neal CR, Holton J and Costerton JW: Biliary stent blockage with bacterial biofilm. A light and electron microscopy study. Ann Intern Med 108: 546-553, 1988

12. Ganderton L, Chawla J, Winters C, Wimpenny J and Stickler D: Scanning electron microscopy of bacterial biofilms on indwelling bladder catheters. Eur J Clin Microbiol Infect Dis 11: 789-796, 1992.

13. Zee KY, Samaranayake LP and Attström R: Scanning electron microscopy of microbial colonization of 'rapid' and 'slow' dental-plaque formers in vivo. Arch Oral Biol 42: 735-742, 1997.

14. Calenic B, Greabu M, Caruntu C, Nicolescu MI, Moraru L, Surdu-Bob CC, Badulescu M, Anghel A, Logofatu C and Boda D: Oral keratinocyte stem cells behavior on diamond like carbon films. Rom Biotechnol Lett 21: 11914-11922, 2016.

15. Molven O, Olsen I and Kerekes K: Scanning electron microscopy of bacteria in the apical part of root canals in permanent teeth with periapical lesions. Endod Dent Traumatol 7: 226-229, 1991.

16. Lomcali G, Sen BH and Cankaya H: Scanning electron microscopic observations of apical root surfaces of teeth with apical periodontitis. Endod Dent Traumatol 12: 70-76, 1996.

17. Silness $J$ and Loe H: Periodontal disease in pregnancy. II. Correlation between oral hygiene and periodontal condition. Acta Odontol Scand 22: 121-135, 1964.

18. Glickman I: Bifurcation involvement in periodontal disease. J Am Dent Assoc 40: 528-538, 1950.

19. Leonardo MR, Rossi MA, Silva LA, Ito IY and Bonifácio KC: EM evaluation of bacterial biofilm and microorganisms on the apical external root surface of human teeth. J Endod 28: 815-818, 2002.

20. Brady JM: A plaque-free zone on human teeth-scanning and transmission electron microscopy. J Periodontol 44: 416-428, 1973.

21. Noguchi N, Noiri Y, Narimatsu M and Ebisu S: Identification and localization of extraradicular biofilm-forming bacteria associated with refractory endodontic pathogens. Appl Environ Microbiol 71: 8738-8743, 2005.

22. Friedman MT, Barber PM, Mordan NJ and Newman HN: The 'plaque-free zone' in health and disease: A scanning electron microscope study. J Periodontol 63: 890-896, 1992.

23. Bass CC: A demonstrable line on extracted teeth indicating the location of the outer border of the epithelial attachment. J Dent Res 25: 401-415, 1946.

24. Saglie R, Johansen JR and Tollefsen T: Plaque-free zones on human teeth in periodontitis. J Clin Periodontol 2: 190-197, 1975.

25. Vrahopoulos TP, Barber PM and Newman HN: The apical border plaque in chronic adult periodontitis. An ultrastructural study. I. Morphology, structure, and cell content. J Periodontol 63: 243-252, 1992.

26. Ribeiro FC: Distribution of bacteria in the mineralized structures of teeth with pulp necrosis and apical granuloma. Bauru, Sao Paulo: Faculdade de Odontologia de Bauru, Universidade de Sao Paulo: 172, 1997.

27. Siqueira JF Jr, Rôças IN, Souto R, de Uzeda M and Colombo AP: Checkerboard DNA-DNA hybridization analysis of endodontic infections. Oral Surg Oral Med Oral Pathol Oral Radiol Endod 89: 744-748, 2000.

28. Ricucci D and Siqueira JF Jr: Fate of the tissue in lateral canals and apical ramifications in response to pathologic conditions and treatment procedures. J Endod 36: 1-15, 2010.

29. Nakano-Hasegawa M, Yammazaki S, Kaneda Y, Takizawa H, Maeda $\mathrm{N}$ and Nakamura S: The formation of biofilms by microorganisms isolated from infected root canals. J Endod 25: 299, 1999. 
30. Sundqvist G: Bacteriological studies of necrotic dental pulps Umeå University Odontol Dissertation, No. 7, University of Umeå, Umeå, Sweden, 1976. https://www.diva-portal.org/smash/ get/diva2:719968/FULLTEXT02.pdf.

31. Walton RE and Ardjmand K: Histological evaluation of the presence of bacteria in induced periapical lesions in monkeys. J Endod 18: 216-227, 1992.

32. Takemura N, Noiri Y, Ehara A, Kawahara T, Noguchi N and Ebisu S: Single species biofilm-forming ability of rootcanal isolates on gutta-percha points. Eur J Oral Sci 112: 523-529, 2004

33. Dahle UR, Tronstad L and Olsen I: Characterization of new periodontal and endodontic isolates of spirochetes. Eur J Oral Sci 104: 41-47, 1996.

34. Felippe WT, Ruschel MF, Felippe GS, Pozzobon MH and Felippe MC: SEM evaluation of the apical external root surface of teeth with chronic periapical lesion. Aust Endod J 35: 153-157, 2009.

35. Quirynen M, Bollen CM, Vandekerckhove BN, Dekeyser C, Papaioannou W and Eyssen H: Full- vs. partial mouth disinfection in the treatment of periodontal infections: Short-term clinical and microbiological observations. J Dent Res 74: 1459-1467, 1995.
36. Rocha CT, Rossi MA, Leonardo MR, Rocha LB, Nelson-Filho P and Silva LA: Biofilm on the apical region of roots in primary teeth with vital and necrotic pulps with or without radiographically evident apical pathosis. Int Endod J 41: 664-669, 2008.

37. Kolenbrander PE, Ganeshkumar N, Cassels FJ and Hughes CV: Coaggregation: Specific adherence among human oral plaque bacteria. FASEB J 7: 406-413, 1993.

38. Mouton C, Reynolds HS and Genco RJ: Characterization of tufted streptococci isolated from the 'corn cob' configuration of human dental plaque. Infect Immun 27: 235-245, 1980.

39. Listgarten MA: Structure of the microbial flora associated with periodontal health and disease in man. A light and electron microscopic study. J Periodontol 47: 1-18, 1976.

(i) (9) This work is licensed under a Creative Commons Attribution-NonCommercial-NoDerivatives 4.0 International (CC BY-NC-ND 4.0) License. 